\title{
The Systematic Use of Fibrin-Based Biological Adhesive to Prevent Leakage Due to Healing Defects in Rectal Anastomosis Significantly Reduces Costs
}

\author{
Jesús Lago Oliver ${ }^{1, ~ *, ~ S a l v a d o r ~ A r g u d o ~ G a r i j o ², ~ M a u r i c i o ~ B u r n e o ~ E s t e ́ v e s ~}{ }^{1}$, \\ Marta Cuadrado Ayuso ${ }^{1,4}$, Fernando Turégano Fuentes ${ }^{1}$, Araceli Casado Gómez \\ ${ }^{1}$ Surgery Department, University Hospital Gregorio Marañón, Madrid, Spain \\ ${ }^{2}$ Surgery Department, Southeast University Hospital Arganda del Rey, Madrid, Spain \\ ${ }^{3}$ Pharmacoeconomics \& Outcomes Research Iberia, Madrid, Spain \\ ${ }^{4}$ Basic Health Sciences Department, University Rey Juan Carlos, Madrid, Spain \\ Email address: \\ jesus.lago@salud.madrid.org (J. L. Oliver)
}

\section{To cite this article:}

Jesús Lago Oliver, Salvador Argudo Garijo, Mauricio Burneo Estéves, Marta Cuadrado Ayuso, Fernando Turégano Fuentes, Araceli Casado Gómez. The Systematic Use of Fibrin-Based Biological Adhesive to Prevent Leakage Due to Healing Defects in Rectal Anastomosis Significantly Reduces Costs. Journal of Surgery. Vol. 3, No. 2, 2015, pp. 12-17. doi: 10.11648/j.js.20150302.12

\begin{abstract}
Objective: To analyse hospital costs in the pre-, and intra- and post-operative periods associated with patients undergoing rectal resection with anastomosis, comparing the costs per patient with and without the use of fibrin-based biological adhesive(Tissucol Duo ${ }^{\circledR}$ ). Methods: The cost analysis was designed with a subsample of 37 patients who underwent rectal anastomosis in a randomised, single-blind, controlled, parallel comparison between two groups, to evaluate the effectiveness of fibrin-based biological adhesive used to prevent anastomotic leakage. The total costs included diagnostic tests, laboratory tests, hospital stay, adhesive cost, surgery, reintervention and drug treatment. Results: The patients had a mean age of 64.33 years, with a higher proportion of men $(62.2 \%)$. The study groups were homogeneous and comparable. The average total cost in the group with biological adhesive was $€ 10,304.84$ compared to $€ 17,845.12$ in the group without biological adhesive. Significant differences were found in the average cost of reintervention between groups: $€ 119.76$ with adhesive vs. $€ 639.20$ for the control group. Conclusions: The total cost decreased by $42 \%$ in the group in which a biological adhesive was applied compared to the group in which the adhesive was not applied. This percentage represented a difference of $€ 7,540.28$ in the total average cost per patient.
\end{abstract}

Keywords: Cost Analysis, Rectal Anastomoses, Fibrin-Based Biological Adhesive

\section{Introduction}

Serious post-operative complications can occur in gastrointestinal surgery, such as anastomotic dehiscence and fistula formation, collectively described as "anastomotic healing impairment". The presence of these complications is influenced by multiple factors, including surgical technique, blood supply, segment quality of the anastomotic tract, local or systemic infection and the nutritional status of the patient, as well as by other conditions, controllable or not, before, during and after the intervention, such as the medication the patient might receive in the postoperative period[1]. It is necessary to use methods to promote healing in patients in whom these factors are not controllable to prevent the occurrence of fistula and dehiscence, which can cause considerable morbidity and, in the worst scenario, patient death [2]. However, it is also common to find subclinical leaks that go unnoticed to the doctor and healthcare staff, which may or may not present negligible clinical signs such as a self-limited febrile syndrome or postoperative ileus. These anastomotic leaks, although are usually self-limited and can be controlled without treatment, occasionally motivate readmissions and emergency reinterventions in critical situations. [3,4]

Fibrin-based biological adhesives were designed to mimic finals stages of the natural coagulation cascade, forming a stable physiological fibrin clot that assists hemostasis and wound healing. The fibrin clots formed by these products, mainly derived from blood plasma and containing fibrinogen 
and thrombin, are similar to normal blood clots and are naturally degraded by the body's enzymes.[5]

In Spain fibrin-based biological adhesives are authorised for use in clinical practice for various indications. One of them is adjuvant treatment to achieve hemostasis in diffuse bleeding and to achieve tissue sealing and/or adhesion in surgical treatment. In this regard, fibrin-based biological adhesive is being used in clinical practice by many gastrointestinal surgeons to prevent fistula formation in gastrointestinal anastomoses, achieving a high percentage of success in a short period of time [6,7].

Numerous studies have suggested a possible relationship between the use of fibrin-based biological adhesives in gastrointestinal anastomoses and the prevention of complications In many cases, they have concluded that fibrin-based biological adhesive reduces the occurrence of postoperative fistula. However, most of these studies were not controlled, so they lacked sufficient power to affirm this hypothesis and recommend the systematic use of adhesives in gastrointestinal anastomoses as a method of preventing leakage [8-14].

As no relevant study was found by our group showing that adhesives can prevent anastomotic leakage, we conducted a randomised clinical trial, comparing two groups of high-risk gastrointestinal anastomoses patients who were assigned to the control group or to the fibrin-based biological adhesive group. The study was conducted to demonstrate scientific evidence showing that fibrin-based biological adhesive prevents postoperative anastomotic healing defects that present as fistulas or dehiscence and to prove with the same level of evidence that they does not negatively influence the patient postoperative course.

Few studies have evaluated the costs associated with the use of fibrin-based biological adhesives. One published in 2006, concluded that the endoscopic treatment of fistulas with biological adhesive has a high success rate without complications and helps to accelerate the healing of fistulas, lowering costs [15].

In the current socio-economic situation, in which there are limited resources available and the sustainability of the public health system is under discussion, we need to demonstrate effective management to improve patient treatment. Therefore, in this analysis, we estimated the costs associated with the management of high-risk patients undergoing rectal resection with gastrointestinal anastomoses comparing the costs with and without the use of fibrin-based biological adhesive (Tissucol Duo $^{\circledR}$ ) as a method of leakage prevention in these anastomotic healing defects, once the results of our trial have demonstrated their clinical efficacy.

\section{Methods}

This cost analysis was performed based on data from a multicentre, randomised, single-blind, controlled, parallel comparison between groups $(\mathrm{N}=104)$, phase IV clinical trial. In this trial, we evaluated the effectiveness of a fibrin-based biological adhesive (Tissucol Duo ${ }^{\circledR}$ ) in preventing leakage due to healing defects in high-risk gastrointestinal anastomoses, where healing defects are expected to be greater than $4 \%$ [1]. The study population included patients from the University General Hospital Gregorio Marañón, San Carlos University Hospital and Southeast University Hospital, all belonging to the Community of Madrid (Spain), who underwent gastrointestinal anastomoses from March 2007 to September 2010. The clinical trial (PROTISSUCOL001, registration number 25/06) was approved by the Committee of Ethics and Clinical Research at each institution, and by the Spanish Agency of Medicines, registered at www.clinicaltrials.gov with identification number NCT0130685.1

The study design and the existence of inclusion and exclusion criteria ensured that the distribution of patients with regard to their clinical situation and anastomotic risk was homogeneous between groups, eliminating potential selection bias. It was also determined that the groups were statistically homogeneous and therefore comparable after randomisation [1].

To collect the required study parameters, a Data Collection Notebook was used. The parameters were collected prospectively during hospitalization and at different reviews until patient discharge.

Of the 104 patients included in the trial, we selected the subsample of patients who underwent rectal anastomoses. Of the 39 patients in this subsample, 2 were removed because not all the information necessary for carrying out cost analysis was available. Therefore, this analysis included a total of 37 patients (Table 1). In this subsample, comparative cost analysis was performed between patients who received fibrin-based biological adhesive (interventional group) and patients who did not receive it (control group).

Table 1. Demographic and clinical characteristics of patients (interventional and control group).

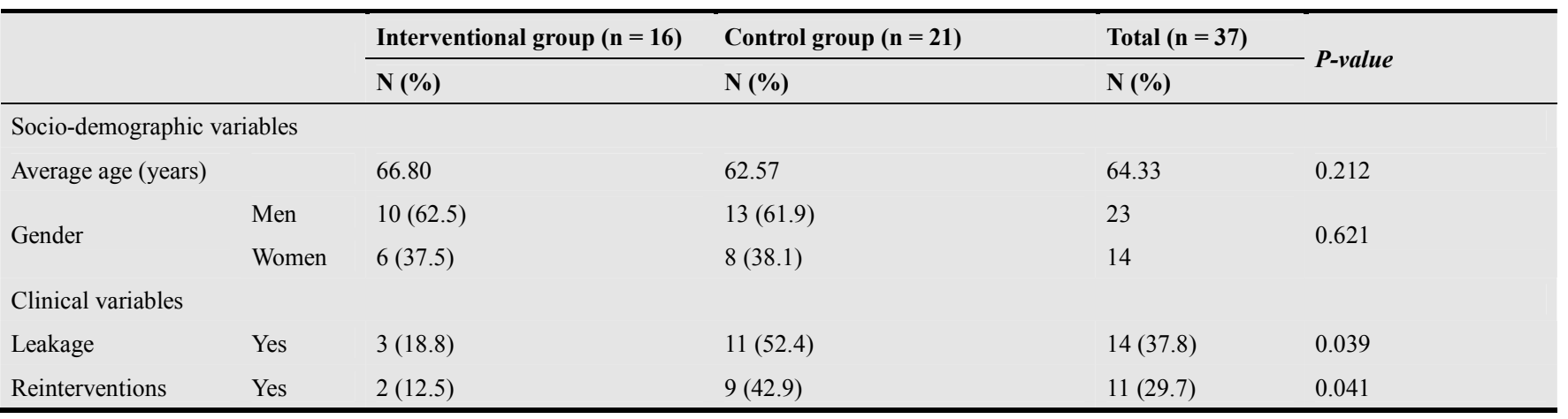




\subsection{Time Horizon}

The following periods were established in this cost analysis: one preoperative period between initial admission and surgery, and an intraoperative and postoperative period from surgery to hospital discharge. The latter also included the post-reintervention period in patients who were reoperated.

\subsection{Resources and Costs}

The total cost per patient was estimated based on data about individual resource use for each one, multiplied by the unit cost of each of the identified resources. The resources considered were the diagnostic tests, laboratory tests, hospital stay (duration and hospitalisation unit), surgery performed (type and duration), reintervention, use of biological adhesive and drug treatment.

The hospital stays were classified according to the hospitalisation unit and the number of days each patient was hospitalised in the unit. The surgeries were differentiated into open and laparoscopic, and the duration, in minutes, was recorded. For laparoscopic surgery, the cost of laparoscopic material for each intervention was added to the cost of its duration in minutes. In the analysis of reinterventions, the cost related to the first or subsequent reintervention, if any, was analysed for each patient.
Tissucol Duo ${ }^{\circledR}$ is a two-component fibrin sealant matrix. Component 1 is a sealer protein solution containing fibrinogen (as clottable protein) $45.5 \mathrm{mg}$ and aprotinin (synthetic) 1500 KIU. The second component is a thrombin solution containing thrombin $250 \mathrm{IU}$ and calcium chloride $20 \mu \mathrm{mol}$. Both components should be mixed immediately prior to use to give two reconstituted solutions in separate containers ready for application using through an appropriate delivery system or device, mainly as spray, in order to provide a similar thin, uniform layer of fibrin sealant in endoscopic procedures. [16] The required dose is related to the surface needed to be cover. In the present study it was considered the use of Tissucol Duo ${ }^{\circledR}$ $5 \mathrm{~mL}$ containing a total volume of $10 \mathrm{~mL}$ of fibrin-based biological adhesive, although less adhesive was used for some patients.

For the drug therapy cost in the postoperative period, the average drug daily cost was calculated and multiplied by the length of hospitalization of each patient. The drug cost was calculated based on the ex-factory price [17]. The unit costs of non-drug healthcare resources were obtained from a Spanish health care cost database [18]. Table 2 lists the unit costs of resources considered.

All costs included in the analysis are expressed in euros $(€)$ of the year 2012 .

Table 2. Average use of health resources per patient in the intra-postoperative period and procedure unit costs ( $\epsilon$, Year 2012).

\begin{tabular}{|c|c|c|c|c|}
\hline Health resource & & Interventional group & Control group & Unit cost (€) \\
\hline \multicolumn{5}{|l|}{ Intra-operative procedure } \\
\hline Fibrin-based biological adhesive & $\mathrm{N}(\%)$ & 1 vial of $5 \mathrm{~mL}(100 \%)$ & - & 203.56 (per $5 \mathrm{~mL}$ ) \\
\hline Open & $\mathrm{N}(\%)$ & $7(43.8 \%)$ & $3(14.30 \%)$ & 9.98 (per minute) \\
\hline Laparoscopic & $\mathrm{N}(\%)$ & $9(56.3 \%)$ & $18(85.7 \%)$ & $\begin{array}{l}9.98 \text { (per minute)+ } \\
1,734.94 \text { (material) }\end{array}$ \\
\hline \multicolumn{5}{|l|}{ Diagnostic Tests } \\
\hline Barium enema & $\mathrm{N}(\%) /$ Average per patient & $8(50 \%) / 0.50$ & $9(42.9 \%) / 0.48$ & 141.67 \\
\hline Barium swallow & $\mathrm{N}(\%)$ / Average per patient & $0(0 \%) / 0$ & $1(4.8 \%) / 0.05$ & 127.22 \\
\hline CT scan with intravenous contrast & $\mathrm{N}(\%) /$ Average per patient & $5(31.3 \%) / 0.31$ & $11(52.4 \%) / 0.95$ & 249.89 \\
\hline$N M R$ & $\mathrm{~N}(\%)$ / Average per patient & $0(0 \%) / 0$ & $1(4.8 \%) / 0.05$ & 179.67 \\
\hline Ultrasound & $\mathrm{N}(\%)$ / Average per patient & $0(0 \%) / 0$ & $1(4.8 \%) / 0.05$ & 173.02 \\
\hline Chest X-ray & $\mathrm{N}(\%) /$ Average per patient & $1(6.3 \%) / 0.06$ & $2(9.6 \%) / 0.14$ & 20.90 \\
\hline Abdominal X-ray & $\mathrm{N}(\%) /$ Average per patient & $1(6.3 \%) / 0.06$ & $0(0 \%) / 0$ & 23.24 \\
\hline \multicolumn{5}{|l|}{ Laboratory tests } \\
\hline$C B C$ & $\mathrm{~N}(\%)$ / Average per patient & $13(35.14 \%) / 6.63$ & $18(48.65 \%) / 17.24$ & 9.27 \\
\hline Biochemistry & $\mathrm{N}(\%)$ / Average per patient & $13(35.14 \%) / 6.63$ & $18(48.65 \%) / 17.24$ & 36.85 \\
\hline Coagulation & $\mathrm{N}(\%) /$ Average per patient & $11(29.73 \%) / 6.5$ & $17(45.95 \%) / 17.14$ & 19.27 \\
\hline \multicolumn{5}{|l|}{ Hospital stays } \\
\hline General surgery & $\mathrm{N}(\%) /$ Average per patient & $16(100 \%) / 11.44$ & $18(85.71 \%) / 15.95$ & 345.89 \\
\hline Geriatrics & $\mathrm{N}(\%) /$ Average per patient & $0(0 \%) / 0$ & $1(4.8 \%) / 0.10$ & 227.59 \\
\hline Resuscitation & $\mathrm{N}(\%)$ / Average per patient & $3(18.75 \%) / 1.06$ & $7(33.33 \%) / 4.43$ & $1,185.47$ \\
\hline$I C U$ & $\mathrm{~N}(\%) /$ Average per patient & $2(12.6 \%) / 0.31$ & $2(9.6 \%) / 0.24$ & $1,185.47$ \\
\hline$P A C U-D S C U$ & $\mathrm{~N}(\%) /$ Average per patient & $1(6.3 \%) / 0.03$ & $0(0 \%) / 0$ & $1,185.47$ \\
\hline
\end{tabular}

NMR: Nuclear magnetic resonance; CT: Computerised Tomography; ICU: Intensive Care Unit; PACU-DSCU: Post-anaesthetic-Day Surgery Care Unit 


\subsection{Statistical Aspects}

The development of the database and statistical analyses were performed using the PASW Statistics ${ }^{\circledR} 18.0$ statistical package. For all analyses of variables, an alpha value $(\alpha)=$ 0.05 was considered, i.e., to estimate a significant difference, the $p$-value of the contrasting statistic should be $\leq 0.05$.

After verifying the information and resolving any inconsistencies, a descriptive analysis was performed. For quantitative variables, mean and confidence interval were calculated. To calculate the significance of the difference between the two groups, the nonparametric Mann-Whitney test was used because the samples to be compared were not of sufficient size (16 patients in the interventional group and 21 patients in the control group).

In the case of qualitative variables, frequency distributions with their corresponding percentages and the average of each resource consumption per patient were calculated.

A comparative analysis of the average total cost was performed for patients on interventional group versus the cost for patients on control group.

\section{Results}

The mean age of the 37 patients included in the analysis was 64.33 years, with no significant differences between groups. The proportion of men was higher, $62.2 \%$ versus $37.8 \%$, without statistically significant difference between groups (Table 1).

Fibrin-based biological adhesive was applied to 16 patients (interventional group) and not applied to 21 patients (control group). There were leaks in the interventional and in the control group. A p-value of 0.039 indicates statistically significant differences between the groups. In the control group, 11 leaks were observed; in the interventional group, only 3 leaks were observed.

\subsection{Costs in the Preoperative Period}

Preoperatively, there were no previous significant differences in the individual health resources or in the total resources between the interventional and the control group $(\mathrm{p}$-value $=0.137)$.

\subsection{Costs in the Intra-Postoperative Period}

Intraoperative cost in both groups were estimated based on type and duration of surgery in each patient (Table 2). The cost of the $5 \mathrm{~mL}$ fibrin-based biological adhesive has been added for all patients in the interventional group. However, the average cost of intraoperative procedure in the interventional group was $€ 3,764.91$ vs. $€ 3,813.38$ in the control group (Table 3).

Table 2 shows the average use per patient of each resource considered, as well as the unit costs. For laboratory and diagnostic tests (except barium enema and abdominal X-ray), the number of tests was higher for the control group. Regarding the hospital stays, except for the Intensive Care Unit and the Post-anaesthetic/Day Surgery Care Unit, the average number of hospitalisation stay was higher for the control group.

The average total cost in the intra-postoperative period was $€ 10,304.84$ for the interventional group and $€ 17,845.12$ for the control group. This difference between groups $(€ 7,540.28)$ resulted in a decrease in total costs of $42.3 \%$ in the interventional group compared to control group.

The resource with the greatest influence on overall cost savings in patients from the interventional group was hospital stays, with a reduction of $€ 5,448.46$ in the average cost per patient in the group with biological adhesive versus the control group (Table 3).

Regarding the average cost per patient of reinterventions, a decrease of $€ 519.44$ was demonstrated in the interventional group versus the control group $(\mathrm{p}$-value $=0.041)($ Table 3$)$.

Table 3. Final costs for the two groups of patients in the intra-postoperative period ( $€$, Year 2012).

\begin{tabular}{|c|c|c|c|c|c|c|c|}
\hline \multirow{3}{*}{ Cost } & \multirow{2}{*}{\multicolumn{2}{|c|}{$\begin{array}{l}\text { Patients } \\
\text { Interventional group }(\mathrm{n}=16)\end{array}$}} & \multirow{2}{*}{\multicolumn{2}{|c|}{$\begin{array}{l}\text { Patients } \\
\text { Control group }(n=21) \\
\end{array}$}} & \multirow{2}{*}{\multicolumn{2}{|c|}{ Total $(n=37)$}} & \multirow{3}{*}{$\begin{array}{l}\% \text { decrease in costs in } \\
\text { patients from interventional } \\
\text { group vs. patients from } \\
\text { control group }\end{array}$} \\
\hline & & & & & & & \\
\hline & $\begin{array}{l}\text { Mean } \\
(95 \% \mathrm{CI})\end{array}$ & $\begin{array}{l}\text { Mean } \\
\%\end{array}$ & $\begin{array}{l}\text { Mean } \\
(95 \% \text { CI })\end{array}$ & $\begin{array}{l}\text { Mean } \\
\%\end{array}$ & $\begin{array}{l}\text { Mean } \\
(95 \% \mathrm{CI})\end{array}$ & $\begin{array}{l}\text { Mean } \\
\%\end{array}$ & \\
\hline Diagnostic tests & $\begin{array}{l}151.68 \\
(71.33-232.04)\end{array}$ & 1.47 & $\begin{array}{l}323.05 \\
(178.17-467.93)\end{array}$ & 1.81 & $\begin{array}{l}248.95 \\
(158.76-339.13)\end{array}$ & 1.71 & 53.0 \\
\hline Laboratory tests & $\begin{array}{l}430.80 \\
(1.17-860.43)\end{array}$ & 4.18 & $\begin{array}{l}1,125.36 \\
(381.87-1,868.85)\end{array}$ & 6.31 & $\begin{array}{l}825.01 \\
(368.50-1,281.52)\end{array}$ & 5.66 & 61.7 \\
\hline Stays & $\begin{array}{l}5,623.18 \\
(2,619.02-8,627.35)\end{array}$ & 54.57 & $\begin{array}{l}11,071.64 \\
(3,721.75-18,421.53)\end{array}$ & 62.04 & $\begin{array}{l}8,715.55 \\
(4,425.29-13,005.81)\end{array}$ & 59.76 & 49.2 \\
\hline Surgery* & $\begin{array}{l}3,764.91 \\
(3,108.35-4,421.46)\end{array}$ & 36.54 & $\begin{array}{l}3,813.38 \\
(3,290.15-4,336.62)\end{array}$ & 21.37 & $\begin{array}{l}3,792.42 \\
(3,402.56-4,182.28)\end{array}$ & 26.00 & 1.3 \\
\hline Reintervention & $\begin{array}{l}119.76 \\
(0-296.88)\end{array}$ & 1.16 & $\begin{array}{l}639.20 \\
(236.34-1,042.05)\end{array}$ & 3.58 & $\begin{array}{l}414.57 \\
(167.48-661.67)\end{array}$ & 2.84 & 81.3 \\
\hline Drug therapy & $\begin{array}{l}214.50 \\
(0-481.26)\end{array}$ & 2.08 & $\begin{array}{l}872.49 \\
(110.12-1,634.87)\end{array}$ & 4.89 & $\begin{array}{l}587.96 \\
(144.13-1,031.79)\end{array}$ & 4.03 & 75.4 \\
\hline Total cost & $\begin{array}{l}€ 10,304.84 \\
(6,314.59-14,295.09)\end{array}$ & 100 & $\begin{array}{l}€ 17,845.12 \\
(8,888.10-26,802.15)\end{array}$ & 100 & $\begin{array}{l}€ 14,584.46 \\
(9,283.07-19,885.86)\end{array}$ & 100 & 42.3 \\
\hline
\end{tabular}

* including the cost related to fibrin biological adhesive for the interventional group. 


\section{Discussion}

Anastomotic leaks are regrettably frequent complications that can occur in 5\%-15\% of patients who undergo this rectal resection [19-21]. This proportion may be increased alarmingly in patients with three or more risk factors, with age being the main risk factor [22].

These complications often require another operation to save the life of the patient and control infection, leading to extended hospitalisation, a significant increase in the use of resources and a marked increase in health costs [20,23] as well as increasing the morbidity and mortality of patients[19,20,23]. Its prevention is therefore highly relevant from a clinical and economical point of view. Fibrin-based biological adhesives are drugs whose efficacy in preventing anastomotic leaks in gastrointestinal anastomoses was demonstrated in the preliminary results of a multicentre clinical trial conducted by our team. When we analysed in detail the subgroup of rectal anastomoses in the preliminary analysis of the trial, we noted that the overall significant differences found between the study groups remained. These findings showed, after the statistical evaluation of homogeneity between the two study populations, that fibrin-based biological adhesives prevent anastomotic leakage.

Therefore, there is evidence both of the clinical impact of this complication and of its possible reduction with the use of fibrin-based biological adhesives. As clinicians, we suspect that the economic impact of leak reduction using biological adhesives is great. The cost analysis performed has attempted to quantify the economic consequences of the use of these drugs to prevent anastomotic leaks, considering only the direct healthcare costs of patient management.

Based on the clinical outcomes obtained, the use of fibrin-based biological adhesives in high-risk anastomoses saves healthcare resources. To the authors' knowledge, this study is the first to have quantified the economic consequences of this type of health intervention, and therefore we cannot compare the outcomes obtained with other published results. However, consistent with the outcomes obtained in this analysis, the authors of one study, who retrospectively analysed 8 cases of anastomotic leakage treated with fibrin-based biological adhesives, suggested that the cost/benefit ratio of dealing with this type of drugs is favourable when considering the costs associated with hospitalisation and treatment required in patients who were not treated with fibrin-based biological adhesives [24]. Our study has shown that the use of these adhesives significantly reduces the cost of reinterventions in the study group; i.e., the average overall cost per patient was reduced from $€ 17,845.12$ to $€ 10,304.84$ in the interventional group, and the percentage likewise decreased. If we consider these data and the frequency of such interventions in our hospitals, the potential annual savings in hospital costs are far from negligible.

At a time when marked healthcare budget cuts are currently being implemented in our country, a warning should be addressed to health managers about the need for such studies and the application of their results in clinical practice as a primary measure of cost control.

One limitation of this study is the small sample size used for the analysis. However, the fact that direct health costs have only been quantified in a time horizon between patient admission and discharge supports the results. For a complete evaluation of the benefits of this therapeutic intervention, it would be advisable for future studies to consider a longer time horizon and a broader perspective. Thus, they would include the cost generated by increased relapse and interventions due to oncologic disease, the cost generated by the extension of sick leave in these patients or even their inability to work, sometimes permanently, in the case of post-operative adverse outcomes.

However, despite the limitation of sample size, we should note that the quantification of resource use in the analysis was prospectively performed and individualised per patient and that the patient cohorts compared were homogeneous, showing no statistically significant differences in the use of health resources in the preoperative period and therefore allowing us to consider the differences in estimated costs in the postoperative period to be directly related to the use of fibrin-based biological adhesive. Therefore, in light of the outcomes, for the rectal anastomoses subgroup, of the clinical trial conducted by our team and of this cost analysis, we recommend the systematic use of fibrin-based biological adhesives for leakage prevention in rectal sutures, not only for its strong clinical impact but for the cost reduction, as demonstrated in the present study.

\section{Conclusions}

The total costs in the interventional group in which fibrin-based biological adhesive was applied were lower than in the control group, with a difference of $€ 7,540.28$ in the total average cost per patient. This difference resulted in a total cost decrease of $42.3 \%$ in the interventional group. Average cost per patient attributable to reintervention showed a decrease of $€ 519.44$ per patient in the interventional group compared to the control group.

\section{References}

[1] Lago Oliver J, Arjona Medina I, Martín García-Almenta E, et al "Use of fibrin based biological glues in the prevention of anastomotic leaks in the high risk digestive tract: preliminary results of the multicentre, prospective, randomised, controlled, and simple blind phase iv clinical trial": 1Protissucol001. Cir Esp. 2012;90:647-655.

[2] Kaidar-Person O, Rosenthal RJ, Wexner SD, et al. "Compression anastomosis: history and clinical considerations.” Am J Surg 2008;195:818-826.

[3] Midura EF, Hanseman D, Davis BR, et al. "Risk factors and consequences of anastomotic leak after colectomy: a national analysis". Dis Colon Rectum 2015;58(3):333-338 
[4] Snijders HS, Bakker IS, Dekker JW, et al. "High 1-year complication rate after anterior resection for rectal cancer". $J$ Gastrointest Surg 2014;18(4):831-838

[5] European Medicines Agency. "Questions and answers on the review of the fibrin sealants Tisseel, Tissucol, Artiss and Beriplast P (and associated names) given by spray application". Available at: http://www.ema.europa.eu/docs/en_GB/document_library/Ref errals_document/Fibrin_sealants_31/WC50013624⒏pdf

[6] Avalos-González J, Portilla-de Buen E, Leal-Cortés CA, et al. "Reduction of the closure time of postoperative enterocutaneous fistulas with fibrin sealant". World $J$ Gastroenterol 2010;16:2793-2800.

[7] Toro A, Mannino M, Reale G, et al. "TachoSil use in abdominal surgery: a review". J Blood Med 2011;2:31-36.

[8] Vakalopoulos KA, Daams F, Wu Z, et al. "Tissue adhesives in gastrointestinal anastomosis: a systematic review". J Surg Res 2013;180:290-300.

[9] Hiura Y, Takiguchi S, Yamamoto K, et al. "Use of fibrin glue sealant with polyglycolic acid sheets to prevent pancreatic fistula formation after laparoscopic-assisted gastrectomy". Surg Today 2013;43:527-533.

[10] Soga K, Ochiai T, Sonoyama T, et al. "Risk factors for postoperative pancreatic fistula in distal pancreatectomy". Hepatogastroenterology 2011;58:1372-1376.

[11] Ikegami T, Maeda T, Kayashima H, et al. "Soft coagulation, polyglycolic acid felt, and fibrin glue for prevention of pancreatic fistula after distal pancreatectomy". Surg Today 2011;41:1224-1227.

[12] Mita K, Ito H, Fukumoto $M$, et al. "A fibrin glue sealing method for the prevention of pancreatic fistula following distal pancreatectomy". Hepatogastroenterology 2011;58:604-608.

[13] Ussat S, Lodes U, Wex C, et al. "Successful closure of a postoperative esophagobronchial fistula following esophageal resection using fibrin glue". Dtsch Med Wochenschr 2013;138:1406-1409.

[14] Dhua AK, Ratan SK, Aggarwal SK. "Chylothorax after Primary Repair of Esophageal Atresia with Tracheo-esophageal Fistula: Successful Management by Biological Fibrin Glue”. APSP J Case Rep 2012;3:16.
[15] Ramón Rábago L, Moral I, Delgado M, et al. "Tratamiento endoscópico de fístulas gastrointestinales con un pegamento biológico tisular". [Endoscopic treatment of gastrointestinal fistulas with biological tissue glue.] Gastroenterol Hepatol 2006;29:390-396.

[16] TissucolDuo ${ }^{\circledR}$. Summary of Products Characteristics. Available at: http://www.aemps.gob.es/cima/pdfs/es/ft/60427/FT_60427.pdf

[17] General Council of Official Pharmaceuticals Colleges. Medicinal Products database. Bot plus web. Available at: www.portalfarma.com

[18] Oblikue consulting. National health cost database. Available at: www.oblikue.com

[19] Ashraf SQ, Burns EM, Jani A, et al. "The economic impact of anastomotic leakage after anterior resections in English NHS hospitals: are we adequately remunerating them?"Colorectal Dis 2013;15:190-198.

[20] Kang CY, Halabi WJ, Chaudhry OO, et al. "Risk factors for anastomotic leakage after anterior resection for rectal cancer". JAMA Surg 2013;148:65-71.

[21] Manta R, Magno L, Conigliaro R, et al. "Endoscopic repair of post-surgical gastrointestinal complications". Dig Liver Dis 2013;45:879-885.

[22] Mäkelä JT, Kiviniemi H, Laitinen S. "Risk Factors for Anastomotic Leakage After Left-Sided Colorectal Resection With Rectal Anastomosis". Dis Colon Rectum 2003;46:653-660.

[23] Frye J, Bokey EL, Chapuis PH, et al. "Anastomotic leakage after resection of colorectal cancer generates prodigious use of hospital resources". Colorectal Dis 2009;11:917-920.

[24] Testi W, Vernillo R, Spagnulo M et al. "Endoscopic treatment of intestinal anastomotic leakage in low anterior resection of the rectum by using fibrin adhesive. Our experience".Minerva Chir 2002;57:683-688. 